\title{
SOCIEDAD CIVIL: MÁS ALLÁ DEL NON PROFIT
}

\section{ICIVIL SOCIETY: BEYOND NON PROFIT}

\author{
Miguel de Haro Serrano \\ Universidad Rey Juan Carlos, Madrid (España) \\ mharo@edicionesyestudios.com
}

Recibido/Received: 30/06/2013

Aceptado/Accepted: 30/09/2013

\section{RESUMEN}

Para un grupo de autores, numeroso y de autoridad probada, la sociedad civil termina en las organizaciones no lucrativas. El non profit es el gran límite, la frontera rígida y estática. El limes del Imperio Romano era bastante menos contundente que el non profit de ciertos académicos. Dura lex, e injusta ley, que deja fuera del ámbito de la sociedad civil a las entidades de la economía social y a todo el mercado que gira en torno a la empresa mercantil. Sin embargo, los nuevos cambios en la misma sociedad y el nuevo concepto de empresa orientada hacia la sociedad sin abandonar la búsqueda del beneficio, plantean una sociedad civil más allá del non profit.

\section{PALABRAS CLAVE}

Nueva sociedad, empresa mercantil, lo económico y lo social, beneficio, non profit, responsabilidad social de la empresa.

\section{SUMARIO}

1. Introducción 2. Una nueva sociedad 3. La empresa mercantil, nuevos perfiles 4. La polémica sobre el mercado. 5. La responsabilidad social de la empresa. 6. Reflexión final. Bibliografía.

\begin{abstract}
For a numerous group of recognized and proved authority authors, the Civil Society is limited to the Non Profit organizations. Non Profit is the great limit, the rigid and static border. The limes on the Roman Empire were less overwhelming than the non profit of certain academics. Dura lex and unfair law that keeps aside from the civil society scope the entities on the social economy and the whole market around mercantile enterprises and businesses. Nevertheless, the new changes in the today's society and the new concept of businesses oriented to the society without forsaking the quest for economic profit, poses a Civil Society beyond non profit.
\end{abstract}

\section{KEYWORDS}

New society, mercantile enterprise, economic and social, profit, non profit, corporate social responsibility.

\section{CONTENTS}

1. Introduction. 2. A new society. 3. Mercantile enterprise, new profiles. 4. Market controversy. 5. Corporate social responsibility. 6. Final reflection. References 


\section{INTRODUCCIÓN}

Inmersos en el día a día se olvida con frecuencia que la sociedad es un fenómeno evolutivo. O, lo que es peor, se acepta con facilidad tal aserto, pero no se aplica ante hechos nuevos. La característica fundamental de la sociedad moderna -dice Leonardo Polo- es su dinamismo, que se manifiesta en una multiplicidad de fenómenos propios de una sociedad inventiva con nuevos modelos de situación social, que aplicados con eficacia descalifican y sustituyen a las minorías que habían ideado los modelos anteriores (2012). Cuantos sostienen que el non profit marca el límite de la sociedad civil olvidan su fenómeno evolutivo dejando fuera de ella a las entidades de la economía social, las llamadas empresas sociales, las empresas de integración y otras tantas cuyo verdadero fin no es el beneficio económico, sino la colaboración, la ayuda o la solidaridad con personas concretas que necesitan esa relación de reciprocidad entre el uno y el otro, yo que te doy la mano y tú que te integras en un nosotros, que es la sociedad civil. ¿Acaso, nos preguntamos, no vivimos en un marco dinámico de una nueva sociedad? ¿El nuevo modo de entender el beneficio empresarial y el nuevo paradigma de responsabilidad social no convierten a la empresa en nuevo actor social? En consecuencia ¿no se abren las fronteras de la sociedad civil y se expande su ámbito a nuevos componentes? No se trata de hacer un análisis exhaustivo de la problemática que planteamos, sino, más bien, de una llamada de atención, de contraste con otras posturas diferentes a las que aquí se exponen, para cotejarlas y, si fuese posible, armonizarlas. Nuestra postura es clara sobre esta materia. El criterio del non profit no es el elemento diferenciador de las entidades que conforman la sociedad civil.

Tocqueville, el gran creador de la teoría del asociacionismo actual, fija en su obra $L a$ democracia en América los principios de estas organizaciones: igualdad, libertad, privacidad, autonomía ante el poder. “¿Qué poder político -se pregunta- podría llevar a cabo las innumerables pequeñas empresas que los ciudadanos americanos ejecutan a diario con las ayudas de las asociaciones?" (2006). Para Tocqueville, a diferencia de otros autores, el non profit no es el elemento diferenciador de las organizaciones que integran la sociedad civil. El autor francés lo fija en el principio de la reciprocidad.

\section{UNA NUEVA SOCIEDAD}

Cuando Alvin Toffler, Daniel Bell o Peter Drucker en la década de 1970 hablaban del nacimiento de una nueva sociedad, simbolizada en menos chimeneas y más preocupación por la información y el conocimiento, podría parecerle a sus coetáneos un proyecto a largo plazo, cuando no un simple disparate. Hoy es un hecho comúnmente aceptado. Primero, la aparición de la computadora, como en otra época fuera la máquina de vapor, y más tarde Internet, con sus múltiples usos, provocaron una nueva revolución industrial, que, como las dos primeras, dio lugar a una nueva sociedad, la sociedad de la información y el conocimiento.

Cambian los paradigmas y pueden traernos cambios en el ámbito propio de la sociedad civil. Los retos, las amenazas y las oportunidades de una sociedad civil, en el espacio y el tiempo concretos de la actual revolución de las tecnologías de la información y la comunicación, pueden ser diferentes a los tiempos de las dos primeras revoluciones industriales. Pueden, también, cambiar las fronteras de la sociedad civil, haciéndose más 
dúctiles, permitiendo la incorporación de nuevos actores sociales, como la economía social o la empresa mercantil, vedados por una buena parte de la doctrina especializada.

\subsection{La sociedad de la información}

¿Qué evoluciones ha experimentado la sociedad industrial hasta convertirse en la sociedad de la información y del conocimiento como una sociedad inventiva con nuevos modelos de situación social? La respuesta la podemos encontrar en distintos autores de los que hemos seleccionado a cuatro, Toffler, Bell, Drucker y Castells, de distintas épocas y diferentes posturas ideológicas.

Alvin Toffler utiliza el término superindustrialismo para describir la naciente sociedad tecnológica. Acuñó esta voz en su obra El shock del futuro (1970). Reconoce que superindustrialismo puede dar lugar a equívocos al interpretarse que una sociedad superindustrial es simplemente una versión a gran escala de la tradicional sociedad masiva e industrializada, un mundo inmenso de chimeneas. Para subsanar el equívoco la denominó tercera ola como expresión de "una sociedad inédita, basada en la alta tecnología, información y nuevos medios para organizarse con designios económicos (1981:36). En sus escritos utiliza, simultáneamente, los dos términos. Conviene recordar que Toffler clasificó la revolución agraria, que comenzara hace diez milenios, como primera ola del cambio histórico; y denominó segunda ola a la revolución industrial, la sociedad que propagara las chimeneas por todo el mundo. Toffler (1985:136) configura un modelo hipotético de superindustrialismo que permite inferir un conjunto de premisas funcionales, a saber: una vez satisfechas las necesidades básicas para la subsistencia, una gran mayoría de personas no persiguen las mismas cosas en la vida, y que la recompensa económica no basta por sí sola para estimularles. La economía de escala tiene unos límites máximos, tanto para una corporación como para un organismo gubernamental. La información es importante, incluso tal vez más que la tierra, el trabajo, el capital y las materias primas. Nos estamos moviendo más allá de la producción fabril masiva hacia un sistema de artesanía manual o cerebral basada en la información y la supertecnología, y que los productos finales de este sistema no son ya millones de artículos estandarizados, idénticos, sino mercancías y servicios a medida del consumidor.

Otro de los futurólogos de la nueva sociedad fue el periodista y sociólogo, Daniel Bell. En su obra The Coming of the Post-Industrial Society, El advenimiento de la sociedad post-industrial (1973:561-563 y 30) plantea una nueva sociedad, la sociedad postindustrial, que la concibe como una profunda transformación de la sociedad industrial, como un tipo ideal que surge de los diversos cambios de la sociedad y en cuya descripción aparecen cinco dimensiones: a) sector económico: el cambio de una economía productora de mercancías a otra productora de servicios (comercio, finanzas, transporte, salud, etc.); b) distribución ocupacional: la preeminencia de las clases profesionales y técnicas.; c) principio axial: la primacía del conocimiento teórico, en donde la sociedad post-industrial se organiza en torno al conocimiento para lograr el control social y la dirección de la innovación y el cambio, esto es, la primacía de la teoría sobre el empirismo; d) orientación futura: la planificación de las tecnologías, ¿cómo se habría mantenido el crecimiento económico sin la nueva tecnología?; e) tomas de decisión: la creación de una nueva tecnología intelectual, cuyo objetivo es, ni más ni menos, el de realizar el sueño de un alquimista social: el sueño de ordenar la sociedad de masas.

La sociedad post-industrial implica el brote de nuevas estructuras y principios axiales: el paso de una sociedad productora de bienes a una sociedad de la información o del 
conocimiento. En la sociedad post-industrial -escribe Bell (1976:550)- en la experiencia del trabajo, los hombres viven cada vez más fuera de la naturaleza y cada vez menos con la maquinaria; viven con otros hombres y se enfrentan entre sí. La sociedad post-industrial es fundamentalmente "un juego entre personas". Un juego entre personas exige una creciente coordinación, una mayor interacción entre ellas:

Durante la mayor parte de la historia humana la realidad era la naturaleza..., Luego la realidad fue la técnica... Ahora la realidad es ante todo el mundo social -ni la naturaleza ni los objetos, solo los hombres- experimentado a través de la conciencia recíproca de uno mismo y de los otros. (1976:550)

Dentro de este concepto de sociedad del conocimiento y de la información hay que incluir el pensamiento de Drucker, que se sitúa entre la economía, la ciencia política, la historia, la teoría del Estado, el buen gobierno -el management- de las organizaciones, sean empresas o entidades no lucrativas, y el mundo social en el que se insertan unas y otras. $\mathrm{Su}$ pensamiento es de gran ayuda en la búsqueda de la delimitación de las nuevas fronteras de la sociedad civil con el mercado. "La sociedad se reestructura a sí misma: cambia su visión del mundo, sus valores básicos, su estructura política y social, sus artes y sus instituciones clave. Cincuenta años más tarde hay un nuevo mundo y quienes nacen entonces no pueden siquiera imaginar el mundo en el que vivieron sus abuelos y en el que nacieron sus padres" (1995a:1). Para el viejo gurú austriaco-americano del management (1995a:13-14; 181-209) la nueva sociedad será a la vez no-socialista, postcapitalista, y seguro que su recurso primario será el saber, lo que significa que tendrá que ser una sociedad de organizaciones. Un sistema en el que competirán y coexistirán las estructuras transaccionales, regionales, de Estado-nación y locales. La teoría del saber de Drucker -una teoría que sitúa el saber en el centro del proceso de producción de riqueza- se puede resumir en estos términos: La nueva teoría económica basada en el saber es bastante diferente de cualquier teoría económica existente, sea keynesiana, neokeynesiana, clásica o neoclásica. El recurso económico básico de esta sociedad es y será el saber. El valor se crea mediante la productividad y la innovación, ambas aplicaciones del saber al trabajo. El saber solo es productivo si se aplica para que se note la diferencia. Hacer que el saber sea productivo, requiere tiempo de gestión. El más difícil de todos los logros de gestión es equilibrar el largo plazo con el corto plazo. Hemos pasado del saber a los saberes y este paso ha dado al saber el poder de crear una nueva sociedad. La tecnología será muy importante, pero esencialmente porque tendrá que obligarnos a hacer cosas nuevas más que porque nos permita hacer mejor las cosas viejas. El auténtico reto que nos espera, no es la tecnología en sí, sino para qué la utilizamos. La sociedad postcapitalista exige estudiar de por vida (1995a:181-209).

Otro autor que resalta la existencia de una nueva sociedad dinámica e inventiva es el español Manuel Castells (1997:47), que establece inicialmente una distinción analítica entre las nociones de sociedad de la información y sociedad informacional. El término sociedad de la información destaca el papel de esta última en la sociedad, pero sostiene que la información, en su sentido más amplio, como comunicación del conocimiento, ha sido fundamental en todas las sociedades, incluida la Europa medieval. En contraste, el término informacional indica el atributo de una forma específica de organización social en la que la generación, el procesamiento y la transmisión de la información se convierten en las fuentes fundamentales de la productividad y el poder, debido a las nuevas condiciones tecnológicas que surgen en este período histórico.

Castells trata de establecer un paralelo con la distinción entre industria e industrial. Una sociedad industrial no es solo una sociedad en la que hay industria, sino aquella en la que 
las formas sociales y tecnológicas de la organización industrial impregnan todas las esferas de la actividad, desde las dominantes hasta los hábitos de la vida cotidiana. El contenido real de sociedad informacional ha de determinarse mediante la observación y el análisis. Castell (1997:27-29) reconoce que una revolución tecnológica, centrada en torno a las tecnologías de la información, está modificando la base material de la sociedad a un ritmo acelerado. Las economías de todo el mundo se han hecho interdependientes a escala global, introduciendo una nueva forma de relación entre economía, Estado y sociedad en un sistema de geometría variable, y hasta el capitalismo ha sufrido un proceso de reestructuración profunda. La revolución de las tecnologías de la información sirve para Castell como análisis de la complejidad de la nueva economía, sociedad y cultura en formación, aceptando de antemano que la tecnología no determina la sociedad, como tampoco la sociedad dicta el curso del cambio tecnológico, sino que el resultado final depende de un complejo modelo de interacción. La tecnología no determina la sociedad: la plasma. Pero tampoco la sociedad determina la innovación tecnológica: la utiliza. Si bien la sociedad, señala, no determina la tecnología, sí puede sofocar su desarrollo, sobre todo por medio del Estado. Para la comprensión de la relación existente entre tecnología y sociedad hay que partir de que el papel del Estado, ya sea deteniendo, desatando o dirigiendo la innovación tecnológica, es un factor decisivo en el proceso general. En buena medida, la tecnología expresa la capacidad de una sociedad para propulsarse hasta el dominio tecnológico mediante las instituciones de la sociedad, incluido el Estado. En el caso de la revolución tecnológica actual, se originó y difundió, no por accidente, en un período histórico de reestructuración global del capitalismo. Así, concluye Castells, la nueva sociedad que surge de ese proceso de cambio es tanto capitalista como informacional (1997:31).

\subsection{La persona, ante todo}

La nueva sociedad ha revalorizado el papel de la persona en esa nueva sociedad, como un fenómeno nuevo en esa sociedad inventiva, la sociedad de la información y el conocimiento. Drucker (1995a:209) considera que en la sociedad postindustrial, la sociedad del saber, la persona es lo esencial, que el saber siempre está encarnado en una persona, transportado por una persona, aumentado o mejorado por una persona, aprendido y transmitido por una persona, empleado, bien o mal, por una persona. Por lo tanto, concluye, el paso a la sociedad del saber convierte la persona en lo esencial y, al hacerlo, plantea retos nuevos, problemas nuevos, cuestiones nuevas y nunca respecto al representante de la sociedad del saber: la persona instruida. El homo digitalis de Drucker es esa persona instruida que se caracteriza por ser el emblema de la sociedad, su símbolo, su arquetipo; ha de ser un concepto universal, porque la sociedad del saber es una sociedad de saberes, global; tiene que ser ciudadano del mundo en su visión, horizontes e información, pero a la vez tendrá que enriquecer su propia cultura local; tendrá que estar preparada para vivir y trabajar simultáneamente en la cultura del intelectual, propia de palabras e ideas, y en la del gestor, que se centra en personas y trabajo; ha de tener la capacidad de comprender los saberes.

Este énfasis en la persona como lo esencial de la nueva sociedad lo encontramos también en el Primer Informe a la Comisión Europea del Foro de la Sociedad de la Información, que reconoce que la soberanía en la sociedad de la información debe corresponder a las personas, por lo que recomienda que nadie quede excluido de la sociedad de la información; que los gobiernos se comprometan a una profunda mejora de 
la calidad de vida de los ciudadanos, asegurando la prestación electrónica de servicios públicos; que la sociedad de la información se convierta en la sociedad del aprendizaje permanente.

En el capítulo XXVI de La tercera ola, Toffler (1981:36) aborda, no sin ciertas reservas, los que pueden ser rasgos de la personalidad del hombre del futuro en la nueva sociedad. Prefiere no hablar del "hombre nuevo", en el sentido de una criatura mítica dotada de toda clase de cualidades, un único modelo ideal que toda la civilización se esfuerza por emular, porque en una sociedad que avanza rápidamente hacia la desmasificación, nada es más inverosímil. Parte del hecho de que los cambios de estructura profunda de la sociedad modifican también las personas, favoreciendo ciertos rasgos y penalizando otros. La tercera ola -dice- no trata de crear algún superhombre ideal, sino de introducir cambios espectaculares en las características distribuidas por nuestra sociedad. Advierte, no obstante, que el mundo en el que rápidamente estamos entrando, es tan ajeno a nuestra experiencia pasada, que todas las especulaciones psicológicas al respecto resultan poco firmes. Lo que se halla absolutamente claro, sin embargo, es que se está operando una confluencia de poderosas fuerzas sociales para alterar nuestro carácter social, hacer surgir ciertos rasgos, suprimir otros y, en el proceso, transformarlos a todos.

¿Cuáles son estas características o atributos que pueden definir al homo digitalis? Toffler señala los poderosos cambios que probablemente influyan en el desarrollo psicológico de la sociedad de la tercera ola. Estos cambios afectan a la crianza de los hijos, a la educación, la adolescencia, el trabajo e incluso al modo en que formamos las imágenes de nosotros. El autor de La tercera ola se fija en cuatro parámetros de la nueva sociedad: 1) crecimiento diferente, porque es probable que el niño de mañana crezca en una sociedad menos centrada en el niño; 2) el nuevo trabajador responderá a las necesidades de los empresarios que precisan cada vez más hombres y mujeres que acepten la responsabilidad, que comprendan como engranar su trabajo con los demás; 3) la ética del consumidor; y 4) la revolución de las comunicaciones en donde una revolución de los nuevos medios de comunicación debe significar una revolución en la psiquis. La característica más revolucionaria de los nuevos medios de comunicación es que muchos de ellos son interactivos.

\section{LA EMPRESA MERCANTIL, NUEVOS PERFILES}

En la teoría económica el mercado es ese lugar ideal en donde se produce una relación de intercambio entre la oferta -productos y servicios que generan las empresas- y la demanda, el conjunto de personas que necesitan un producto o servicio determinado, y que desean y pueden comprarlo. En la economía real, la empresa y las personas son los polos sobre los que gravita el fenómeno del mercado. La empresa es una realidad socioeconómica compleja que es objeto de estudio de varias ramas del conocimiento. Gutenberg (1978:18), por ejemplo, señala entre ellas la economía de la empresa, que se ocupa de los hechos económicos del proceso productivo; la ciencia de la explotación, ligada a los procesos técnicos; la ciencia del trabajo, relacionada con métodos y tiempos, a la vez que se interesa por los problemas referidos a la mejor disposición del trabajo humano en la empresa; la fisiología del trabajo, que investiga el rendimiento del trabajo humano en la empresa; la psicología y la sociología de la empresa, que se ocupa de ella como organización social y que considera al individuo como miembro de un grupo de trabajadores. Es una complejidad que se acentúa, como observa Belardinelli, (2004:183) 
cuando se analiza desde distintos puntos de vista: como organización de recursos humanos y técnicos para la producción de bienes o servicios; como medio de utilización del capital; como una institución dirigida a producir beneficios; como la concreción del espíritu emprendedor; como promoción y tutela del llamado capital humano. Belardinelli añade a estas perspectivas las que se derivan de la teoría de la organización, como las procedentes del estudio del sistema de flujos informativos, de las relaciones de autoridad y poder entre los distintos órganos, y los problemas de tipo psicológico dentro del cuerpo social que es la empresa.

La empresa como realidad social nace y se desenvuelve en un entorno social. Ortega la habría considerado como un ejemplo de realidad radical, porque es raíz de otras realidades que en ella confluyen. Es un ser vivo que nace, crece, se desarrolla y muere, dentro de un marco social, cultural, político y económico, que varía según las circunstancias históricas de cada momento. Desde finales del siglo XVIII hasta la primera guerra mundial, según Vázquez de Prada (1974:II, 11), la economía y, consecuentemente, la empresa, se desarrolla en el marco del sistema capitalista, que se entroniza con la Revolución industrial, que evoluciona. Para Drucker, la sociedad post-capitalista se presenta como una síntesis de la sociedad del saber o del conocimiento y de las organizaciones. Los materialismos economicistas, sean de origen marxista o capitalista, no explican el fundamento de esa nueva sociedad. No deja de reconocer que el capitalismo es un sistema eficaz que consigue los objetivos que se propone, como lo ha demostrado en los logros de la industrialización, sin embargo, como sistema social el capitalismo ha fracasado al poner su fe en el beneficio privado como regulador de la conducta social (1989:23-28). Por el contrario, Weber (2004:61) centra el espíritu del capitalismo en alcanzar el éxito económico: "La ganancia no es un instrumento para satisfacción de necesidades vitales materiales del hombre, sino que más bien el hombre debe adquirir, debe sumar ganancias, porque ese es el objetivo de su vida... Ganar dinero -cuando se hace legalmente- se interpreta, dentro del orden económico moderno, como el resultado y la expresión de la virtud en el trabajo". Para Weber el triunfo del capitalismo no se debe a la plusvalía, ni al maquinismo, como pretendía Marx, sino a la eficiencia social de unos valores nacidos en la ética protestante, que van mucho más allá del puro elemento económico. De esta misma opinión era su amigo Sombart, pero atribuyendo el auge del capitalismo al judaísmo. Weber define a los empresarios como hombres heroicos.

Drucker considera que la sociedad de principios del siglo XX se orientaba hacia una sociedad de las organizaciones en donde la empresa, sin dejar de ser una unidad económica, era una organización social y una comunidad: "La sociedad occidental ha abandonado la creencia de que el hombre es fundamentalmente un hombre económico, que sus motivos básicos son motivos económicos y que su satisfacción reside en el éxito económico y en las recompensas económicas. El concepto moral de la naturaleza y fin del hombre, en el que estaba fundada la sociedad mercantil, ha dejado de ser válido. Porque hemos aprendido que la libertad y la justicia no pueden ser realizadas en el ámbito económico ni por medio de él. Hemos aprendido que una sociedad que funcione ya no puede organizarse en el mercado ni por medio de él. A través de su éxito económico el hombre económico se ha hecho a sí mismo no solo superfluo, sino que, además, ha fracasado política, social y metafísicamente" (1995b:90).

La naturaleza del hombre no puede limitarse a un principio únicamente material, reduccionista: "Lo material -insiste Drucker (1995a:90)- lejos de ser el fundamento de la sociedad humana es, sin embargo, un polo de la existencia humana. No es de mayor 
importancia, aunque tampoco de menor, que el otro polo, el espiritual... Los cambios y desarrollos humanos se manifiestan tanto en las artes y en la actividad espiritual del hombre como en la sociedad y en la empresa". Lo económico y lo social son dos postulados por donde transcurre el hombre y la empresa; no vale, pues aceptar un mercado puramente economicista, que establece unos límites rígidos con el sistema u orden social. La empresa está vinculada estrechamente a la sociedad; si bien es una institución autónoma con su estructura y objetivos propios, también es una institución social que sirve a la sociedad; la sociedad contribuye a la estabilidad y supervivencia de la empresa. Así lo ve Drucker: "La empresa está subordinada a la sociedad y, sin embargo, la domina a la vez. Es representativa y decisiva, pero es una institución de nuestra sociedad. Esto significa que las creencias, valores y promesas de la sociedad obligan a la empresa. Significa también que el grado en que la empresa logre o no logre vivir a tono con esas creencias, valores y promesas decidirá el éxito o el fracaso de nuestra sociedad" (1993:224).

Al hilo de esta simbiosis entre empresa y sociedad, pueden formularse dos preguntas: ¿No reside aquí el principio de la responsabilidad social de la empresa? ¿Puede una empresa armonizar la búsqueda del beneficio y servir a la sociedad? La primera obligación de la empresa mercantil es de índole económica. En un sistema de economía de mercado, la empresa, para poder subsistir y crecer, ha de ser rentable, ha de obtener beneficios. El lucro es un objetivo irrenunciable de la empresa y todos sus esfuerzos han de estar encaminados a lograrlo. Antes de que el liberalismo económico convirtiera el lucro en una meta sin límites, Tomás de Aquino admitía la licitud del lucro subordinándolo a fines honestos y limitándolo en la cuantía, a la vez que reconocía la función social del comercio. "Desde el punto de vista económico la empresa es la organización de los factores de producción (capital y trabajo) con el fin de obtener una ganancia ilimitada" (Garrigues, 1976:24). En este sentido se expresan Paul Samuelson (la empresa ha de obtener los máximos beneficios, como recompensa de los riesgos del empresario, como el resultado de las iniciativas e innovaciones, o como discrepancias imprevisibles creadas por la incertidumbre, (1979:675-684); Fernández-Pirla (la empresa privada en el régimen económico capitalista se mueve en función del principio lucrativo de maximización del beneficio esperado, (1962:56); y, en fin, Hernández Martín (1988:147): “la actividad empresarial privada atenderá al objetivo de obtención de beneficios desde una perspectiva cambiante, tanto por la evolución de su estructura interna como por la valoración del contexto social o político en el que se desenvuelve".

Nos aproximamos a una nueva concepción del beneficio empresarial en relación con las exigencias de la sociedad. Así, Drucker (1993:52) considera el beneficio como la recompensa aneja al riesgo que entraña el futuro, fuente de incertidumbres. Sin el concepto de beneficio no se podría hacer frente, de modo racional, al riesgo que es el resultado. La vida económica no es posible sin el beneficio; la rentabilidad es el único criterio para medir el éxito o el fracaso empresarial. La sociedad y la empresa coinciden en evitar pérdidas y obtener beneficios para cubrir los riesgos futuros. La supervivencia de la empresa es un interés social. Para García Echevarría (2011) el beneficio constituye una pieza básica dentro del proceso de desarrollo de las personas, la empresa y la sociedad, pero no es un indicador suficiente para evaluar ni personas, ni empresas, ni sociedad. El papel del beneficio no es una cuestión meramente empresarial, sino que tiene una categoría societaria; el beneficio no es la meta final, pero sí constituye uno de los motores fundamentales de la sociedad. García Echevarría comparte las afirmaciones de Keitel, presidente de la Federación Empresarial Alemana: "Yo me declaro a favor de la afirmación de que la finalidad de la economía no está en la misma economía, sino en su contribución 
humana y societaria”. Así como las palabras de Barton, presidente de Mckinsey: Si el capitalismo que emerge de la crisis es de forma vibrante y renovada nos lo agradecerán las futuras generaciones. Pero, si nosotros lo único que hacemos es meramente cubrir las grietas y retornamos a nuestra visión de la precrisis, no quisiéramos saber lo que los historiadores escribirán en el futuro.

A la vista de todo ello, García Echevarría señala que se configura un nuevo orden económico-social, que exige un proceso de cambio en diferentes magnitudes. Este nuevo orden económico-social está dando lugar a un nuevo paradigma de empresa de acuerdo con la afirmación de Belardinelli (2004:183-184) de que "la empresa no logra su objetivo simplemente con la obtención de beneficios... por encima del beneficio está su cualidad más obvia y también más distintiva: su condición humana, todo lo que tiene que ver con el hombre y que, justamente por eso, hace que la empresa esté llamada a ser digna del hombre".

Sobre esta condición humana, Argandoña (2013) se pregunta si puede vivirse el amor en la empresa. La teoría tradicional -dice- sobre la empresa no deja espacio para el amor en las organizaciones económicas, sin embargo "el amor puede y debe ser vivido como condición para que una empresa lleve a cabo su actividad con eficiencia, haciéndola atractiva para los que participan en ella, y haciendo consistente su acción a largo plazo". El autor distingue diversas variantes de amor que se dan en las empresas: el afecto, que se puede llamar también simpatía, que genera una cierta comunión entre las personas; el compañerismo o la camaradería, que se dan entre personas que comparten experiencias, que hacen algo juntos y que pasan dificultades juntos; la amistad, que es amor mutuo, correspondido, selectivo, se construye sobre un propósito común, y es recíproco, dos amores que son uno, el nosotros. Argandoña construye sobre estos amores su teoría de la empresa, ya que, de un modo u otro, contribuyen, a su desarrollo como comunidades humanas.

\section{LA POLÉMICA SOBRE EL MERCADO}

La configuración clásica de la sociedad en tres sectores presenta al mercado como la antítesis de la sociedad civil. La sociedad civil es lo non profit frente al lucro, que ha sido generado por la actividad económica de la empresa. Salamon es contundente cuando afirma que las cooperativas y las empresas no forman parte de la sociedad civil por tratarse de entidades que persiguen una finalidad de lucro. Frente a esta postura, otros autores contemporáneos sostienen lo contrario.

Rafael Alvira (2004:9) afirma que la empresa es y se considera cada vez más un actor de relevancia central en el entramado de la sociedad civil.

Belardinelli matiza tal afirmación al exigir que la empresa sea civil, en el sentido de "una connotación que impregne todos los ámbitos de la vida social, que aspire a afirmar la idea de que una sociedad será más civil cuanto más respetuosa sea y cuanto más promueva, en todos los niveles, la dignidad, la libertad y los derechos de las personas" (2004:180).

Giner considera el mercado como "el rasgo estructural más sobresaliente" [de la sociedad civil] (1987:58).

Para Pérez-Díaz, la sociedad civil comprende las instituciones sociales, los mercados y las asociaciones, quedando fuera el Estado (1993:76-77). 
En la doctrina clásica, Hegel fundamenta la sociedad civil sobre el sistema de necesidades donde el individuo las satisface por medio de su trabajo y la satisfacción de necesidades de todos los demás (Hegel, párr. 188) El sistema de las necesidades de Hegel es un tratado de economía política. Es lo que entendemos por mercado, que lo sitúa en el ámbito de la sociedad civil, frente a la otra corriente de pensamiento.

\section{1 Ámbito clásico, el mercado no es sociedad civil}

Cohen, Arato, Habermas y Salamon son considerados como exponentes representativos de la teoría que concibe al mercado, junto con el Estado, fuera de la órbita de la sociedad civil. De ellos, los dos primeros autores sitúan la sociedad civil entre la economía y el Estado, integrada por la esfera íntima (especialmente la familia), la esfera de las asociaciones voluntarias, los movimientos sociales y las formas públicas de comunicación. Cohen y Arato ven la sociedad civil como un nuevo paradigma que hará posible la realización de los derechos básicos: libertad, igualdad, democracia, solidaridad y justicia social. Aunque estos dos autores diferencian la economía de la sociedad civil no cierran las fronteras entre ellas, ni tampoco buscan reinsertar a la economía en la sociedad civil, sin embargo aceptan que los principios de la sociedad civil influyan en la sociedad económica. Por otra parte, denuncian la debilitación de la sociedad civil por la expansión de una economía de empresas privadas que, cada vez, tienen menos de liberal, así como por la ampliación excesiva del aparato administrativo del Estado intervencionista (2000:8-11, 39, 43).

Jürgen Habermas sitúa el ámbito de la sociedad civil fuera del Estado y de los procesos económicos. Distingue entre sistema y mundo de la vida. El sistema comprende, por una parte, el poder, que da lugar al subsistema de lo político, y, por otra, el dinero, o sea, el subsistema económico Asimila la sociedad civil a su concepto del mundo de la vida orientado a la solidaridad, en tanto es "una red de acciones comunicativas" (1999b:434). Ésta, a diferencia de la racionalidad meramente instrumental, abandona la esfera individual y sitúa el foco de la acción en la cooperación entre los sujetos. Los actores, movidos por la acción comunicativa, no persiguen la consecución de un fin egoísta, sino que aspiran a coordinarse a través de actos de entendimiento, haciendo posible el reconocimiento recíproco como sujetos (1999a:27). Ese reconocimiento recíproco supone para Habermas que "el igual respeto de cada cual no comprende al similar, sino que abarca a la persona del otro, o de los otros en su alteridad. Y ese solidario hacerse responsable del otro como uno de nosotros se refiere al flexible nosotros de una comunidad (1999c:23). El término sociedad civil, tiene hoy para el autor alemán un significado distinto a la sociedad civil que Hegel había identificado como sistema de las necesidades, como un sistema de trabajo y de tráfico de mercancías propio de una economía de mercado: "El núcleo institucional de la sociedad civil lo constituye esa trama asociativa no estatal y no-económica, de base voluntaria, que ancla las estructuras comunicativas del espacio de la opinión pública en el componente del mundo de la vida ... La sociedad civil se compone de esas asociaciones, organizaciones y movimientos surgidos de forma más o menos espontánea que recogen la resonancia que las constelaciones de problemas de la sociedad encuentran en los ámbitos de la vida privada, la condensan y elevándola, por así decir, el volumen o voz, la transmiten al espacio de la opinión pública-política..." (1999b:447).

Habermas reconoce que el espacio de acción de la sociedad civil en los regímenes democráticos es limitado, porque los actores ejercen influencia, pero no poder político. La sociedad civil tiene el poder comunicativo para influenciar al poder administrativo, 
mientras que su influencia en la economía es prácticamente nula, porque ésta se desarrolla enteramente bajo la lógica instrumental (1999b:450).

En Salamon encontramos una separación tajante entre sociedad civil y mercado. Sus investigaciones globales sobre el tercer sector, o sociedad civil, le otorgan una gran autoridad en esta materia. El non profit es el criterio esencial que diferencia el espacio propio de la sociedad civil y el del mercado. Concibe la sociedad civil organizada como una de las áreas del sentimiento humano; un área invisible, oculta, mucho menos explorada que las selvas amazónicas. La contempla como una enorme colección de instituciones que existen entre el mercado y el Estado, como "un grupo complejo de instituciones" que incluye muchos y variados tipos de organismos, agencias de servicios sociales, universidades, hospitales, clubes deportivos, con una gran diversidad de objetivos.

Lo que une a estas entidades tan diferentes entre sí, no reside, para Salamon, en las actividades que realizan, sino en los valores que postulan, que son múltiples. Además del altruismo, la compasión y una sensibilidad frente a los necesitados, lo que subyace son dos valores asentados en el corazón de lo que este área significa: i) en primer lugar, "la idea de la iniciativa individual para el bien público, la idea de que las personas tienen la capacidad de tomar una iniciativa propia sin que nadie les tenga que pedir que actúen por el bien público. Tal como el mercado significa el mecanismo de la iniciativa individual en el bien privado, el tercer sector representa el mecanismo de la iniciativa individual en el bien público; ii) en segundo lugar "existe el valor de la solidaridad, o comunidad, que corresponde a la idea de que las personas tienen obligaciones recíprocas, no solamente con ellas mismas, que poseen una obligación más amplia con la sociedad de la cual son parte..." (2001:47). Salamon (2001:52) se pregunta: ¿por qué nos interesa la sociedad civil? ¿cómo contribuye a nuestra vida, a nuestra economía, a nuestra sociedad? ¿cuáles son estas contribuciones? ¿qué evidencia existe de que las organizaciones sin fines de lucro contribuyen más en estos campos que otras instituciones? Identifica cinco funciones diferentes, asociadas a estas organizaciones: la función del servicio, es decir, están produciendo servicios de mejor calidad, o llegando a los niveles más bajos de la sociedad; el rol de promoción, es decir, poner temas en conocimiento del público; el rol de agente comunitario; el rol del capital social, de construir lazos de confianza y reciprocidad, propuesto por Robert Puttnam.

Salamon, como otros autores, no considera que el mercado sea un elemento componente de la sociedad civil. ¿Por qué? Sostiene, cuando describe el sentido del non profit distributing, que las organizaciones no pueden ser comerciales y que no pueden distribuir beneficios entre los directivos, los accionistas y los ejecutivos. Admite que las organizaciones de la sociedad civil puedan generar beneficios en el transcurso de sus operaciones, pero cualquiera de esos beneficios debe reinvertirse en los objetivos de la organización. Como consecuencia de este principio, el ámbito de la sociedad civil engloba tanto a organizaciones religiosas como seculares; organizaciones con empleados remunerados y aquellas que tienen voluntarios que no cobran; y organizaciones que realizan funciones relevantes -como la abogacía, la cultura, la protección medioambientales, los derechos humanos, religión, defensa de intereses personales y opciones políticas- y aquellas que desempeñan servicios esenciales, como la previsión de la salud, la educación o servicios sociales. Incluye también los movimientos sociales y actividades cooperativas de carácter comunitario que sirven fundamentalmente a objetivos solidarios. Por el contrario, Salamon y su equipo de colaboradores del Center for Civil Society Studies, de la Universidad Johns Hopking, de Estados Unidos "excluyen 
intencionadamente" del ámbito propio de la sociedad civil a las organizaciones gubernamentales, los negocios privados, las cooperativas en general, las cooperativas comerciales y las mutuas (2011:8).

\subsection{Nuevas fronteras de la sociedad civil organizada}

A las posturas descritas sobre el carácter restrictivo del ámbito de la sociedad civil, que dejan fuera tanto al Estado como al mercado, se oponen las de otros autores que, por el contrario, aceptan el mercado como componente importante de la sociedad civil. Así, Pérez-Díaz (1993:76-81) distingue entre sociedad civil sensu lato, o en sentido amplio, (o sociedad civil uno) y sociedad civil dos. En el sentido amplio, la sociedad civil abarca al Estado, a un conjunto de instituciones sociales como el mercado, a asociaciones voluntarias y a una esfera pública. Este concepto lo hemos visto en Adam Ferguson (1974) como sinónimo de sociedad política. La sociedad civil, en sentido restringido, (sociedad civil dos) excluye al Estado y sus instituciones, y se reduce a las instituciones sociales, como el mercado y las asociaciones, y a la esfera pública. El Estado y la sociedad civil se sitúan uno frente al otro, como dos esferas distintas, pero implicadas en una serie de intercambios y colaboraciones. "Señalar (1993:135) -dice textualmente- los límites del Estado es, por tanto, mostrar el potencial de la sociedad civil". Pérez-Díaz justifica este esquema estructural de sociedad civil, donde incluye tanto a los mercados como a las asociaciones voluntarias, por la complejidad interna de la sociedad civil y su peculiar combinación de cooperación y competencia entre sus unidades constituyentes. Este sistema de cooperación y competencia afecta a gran número de agentes autónomos, abarca una amplia variedad de áreas de la vida económica, social, política y cultural, y dispone de un alto nivel de autocoordinación.

Recuerda Keane, (1992:51-52) que el concepto de una sociedad civil separada del Estado es una invención desarrollada por Hegel y el joven Marx, y que se refiere al "mundo de la necesidad, a la economía burguesa de individuos productores y consumidores". Es decir, al ámbito de la economía. Ahora bien, Keane (1992:33) no restringe el ámbito de la sociedad civil, como si fuera sinónimo de una esfera no estatal, garantizada legalmente y dominada por corporaciones capitalistas y familias patriarcales. Lo amplía con un vital significado adicional, que es "convertirse en una esfera no estatal que incluye una variedad de esferas públicas, unidades productivas, domésticas, organizaciones de ayuda mutua y servicios basados en la comunidad, que están legalmente garantizados y se autogobiernan". Adela Cortina comparte esta teoría de integración del mercado en el ámbito de la sociedad civil en estos términos: "El contenido de la sociedad civil vendría constituido por las organizaciones e instituciones del mundo económico, por las asociaciones voluntarias -comunidades adscriptivas y voluntarias, asociaciones cívicasy por la esfera de la opinión pública. En su seno se dan la mano la racionalidad estratégica y la comunicativa, la competencia de intereses y la cooperación, el individualismo egoísta y la solidaridad. Pero todo ello dentro de un contexto de voluntariedad y pluralismo, que es su gran baza" (1998b:378).

La sociedad civil -acepta García Marzá- $(2008: 30,35,40)$ necesita al Estado para poder funcionar, pero es independiente en sus iniciativas, propuestas y capacidad organizativa. Critica a Habermas y Kaldor por la exclusión que hacen de la economía, porque es dejar sus instituciones fuera de la crítica $\mathrm{y}$, con ello, renunciar a toda posibilidad de transformación y cambio que vengan de las otras esferas. La exclusión de las instituciones económicas da lugar a que la teoría de la democracia pierda uno de sus pilares básicos, al quedar fuera de análisis los ámbitos de acción, donde se establecen la gran mayoría de las 
relaciones sociales y se produce el poder económico y social. "En los ámbitos de la sociedad civil -dice García Marzá- nos encontramos con intereses particulares (prestigio, dinero, etc.), pero también podemos encontrarnos con intereses comunes (profesionales, corporativos, etc.) y con intereses generales o universales (reconocimiento, dignidad, etc.)". En definitiva, García Marzá incluye en una tipología de los actores de una sociedad civil a los antiguos movimientos sociales, en su papel de transformación social, como los obreros; los nuevos, como el pacifismo, ecologismo o feminismo; organizaciones cívicas y solidarias; redes cívicas; nuevos movimientos anticapitalistas, etc.

La teoría de Michael Walzer supone una postura intermedia entre ambas corrientes. De entrada, no acepta la economía como un integrante del ámbito de la sociedad civil, pero la acepta con unas correcciones. Walzer (2001) concibe la sociedad civil y el Estado como formaciones cruciales donde se desarrolla nuestra vida. La vida buena solo puede vivirse en la sociedad civil, a la que considera como "el ámbito de la fragmentariedad y el conflicto, pero también de las solidaridades concretas y auténticas... somos sociables por naturaleza, y lo éramos antes de convertirnos en seres políticos o económicos". El mercado no es un lugar propicio para ejercer la solidaridad social, no puedo ayudar a otros sin reducir mis propias opciones, no se puede ejercer la ayuda mutua. "El mercado crea desigualdad... Sin embargo, allí donde el mercado se imbrica en la sociedad civil, es controlado políticamente y permanece abierto a las iniciativas, tanto privadas como comunales pueden paliarse estos resultados desigualitarios". En resumen, Walzer, acepta al mercado siempre que esté anclado en una red de asociaciones.

La sintonía con estas posturas favorables a la inclusión del mercado dentro de las fronteras, siempre dúctiles y no rígidas, de la sociedad civil nos conduce a discrepar del carácter restrictivo que Salamon otorga al concepto de non profit. En consecuencia, no aceptamos la exclusión de las entidades que integran la economía social (cooperativas, mutuas y asociaciones) y la empresa mercantil, porque no cumplan el requisito del non profit en los términos que él lo concibe. Pensamos que, reducir el ámbito propio de la sociedad civil a las organizaciones no lucrativas, es limitarlo excesivamente. Salamon olvida que las organizaciones empresariales construyen, día a día, la sociedad civil mediante la colaboración y el apoyo a las entidades non profit.

\section{LA RESPONSABILIDAD SOCIAL DE LA EMPRESA}

Para completar los cambios que está experimentando la empresa comercial, descritos en el punto 3 de este trabajo, hay que tener en cuenta el nuevo paradigma empresarial que, cobra con el tiempo un mayor reconocimiento en el mercado y la sociedad, avalando a la empresa como actor de la sociedad civil. La responsabilidad social de la empresa (RSE) comprende un conjunto de innovaciones y procesos que las empresas adoptan de forma voluntaria, de cara a una mayor orientación e integración en las necesidades sociales y una gran preocupación por atender debidamente a los grupos de interés de las empresas, los stakeholders.

La Comisión de las Comunidades Europeas publicó, en julio de 2001, el Libro Verde: Fomentar un marco europeo para la responsabilidad social de las empresas. Entiende la responsabilidad social de las empresas como "un concepto con arreglo al cual las empresas deciden voluntariamente contribuir al logro de una sociedad mejor y un medio ambiente más limpio". En España, siguiendo las iniciativas de la Comisión de las Comunidades 
Europeas, en junio de 2006, el Congreso de los Diputados aprobó, por unanimidad, el Libro Blanco de la RSE, con objeto de potenciar y promocionar la RSE.

Abundando en estas ideas, la doctrina social de la Iglesia católica, y más específicamente la encíclica Caritas in veritate (29 de junio de 2009), de Benedicto XVI, reconoce que hay "cambios profundos en el modo de entender la empresa. Antiguas modalidades de la vida empresarial van desapareciendo, mientras otras más prometedoras se perfilan en el horizonte ... se está extendiendo la conciencia de la necesidad de una responsabilidad social más amplia de la empresa... la gestión de la empresa no puede tener en cuenta únicamente el interés de sus propietarios, sino también el de los otros sujetos que contribuyen a la vida de la empresa: trabajadores, clientes, proveedores de los diversos elementos de producción, la comunicación de referencia..." (párr. 40). Cuando señala que "se ha de evitar que el empleo de recursos financieros esté motivado por la especulación, en vez de por la sostenibilidad de la empresa a largo plazo, su propio servicio a la economía real y la promoción de iniciativas económicas, también en los países necesitados de desarrollo", Benedicto XVI está reafirmando la necesidad e importancia de la responsabilidad social de las empresas. E incluso cuando se refiere al "trasvase de competencias del mundo non profit al profit y viceversa" (párr. 41) está señalando un modus operandi de la responsabilidad social de la empresa: la incorporación de la gratuidad en el mercado y la profesionalización de la gestión en las entidades de la sociedad civil.

La nueva Comunicación de la Comisión Europea, del 25 de octubre de 2011, dedicada a la Estrategia renovada de la UE para 2011-2014 sobre la responsabilidad social de las empresas establece una nueva definición, a saber, "la responsabilidad de las empresas por su impacto en la sociedad". Esta Comunicación, dentro del marco Estrategia Europa 2020, reconoce que se trata de un proceso complejo que dependerá de factores diversos, como el tamaño de la empresa y su propia actividad. Asimismo exige un planteamiento estratégico a largo plazo, con modelos empresariales innovadores que desarrollen productos y servicios favorecedores del bienestar social y crear empleos de mayor calidad. Para ello las empresas deben de gozar de cierta flexibilidad para innovar y desarrollar un enfoque de la RSE adecuado a sus circunstancias. La RSE es aplicable a todas las empresas. Respecto al papel de los poderes públicos, la citada Comunicación es taxativa: "el desarrollo de la RSE deben liderarlo las propias empresas" reservando a aquéllos "un papel de apoyo". Los sindicatos y las organizaciones de la sociedad civil deben detectar los problemas, ejercer presión para una mejora de la situación y cooperar con las empresas para la búsqueda de soluciones.

\section{REFLEXIÓN FINAL}

El concepto de non profit no es el límite, la frontera rígida y estática de la sociedad civil organizada. Las organizaciones non profit pueden constituir el núcleo duro de la sociedad civil, pero la empresa y el mercado también están dentro de los límites de la sociedad civil.

\section{BIBLIOGRAFÍA}

ALVIRA, R. (2004), Empresa y sociedad civil, Madrid, Fundación Iberdrola. 
ARGANDOÑA, A. (2013),"El amor en la empresa", en Comentarios sobre Caritas in veritate, Madrid, Aedos.

BELARDINELLI, S. (2004), "La empresa desde el punto de vista de la sociedad civil", en Revista Empresa y Humanismo, vol. VII, 2/04, Instituto Empresa y Humanismo, Universidad de Navarra.

BELL, D. (1973), El advenimiento de la sociedad post-industrial, Madrid, Alianza.

-- (1976), Las contradicciones culturales del capitalismo, Madrid, Alianza.

BENEDICTO XVI (2009), Encíclica Caritas in veritate.

CASTELLS, M. (1997), La era de la información. Economía, Sociedad y Cultura, Vol. 1, Madrid, Alianza.

COHEN, J. L. y ARATO, A. (2000), Sociedad civil y teoría política, México, Fondo de Cultura Económica.

CORTINA, A. (1998a), Ciudadanos del mundo. Hacia una teoría de la ciudadanía, Madrid, Alianza.

-- (1998b), "Sociedad civil", en 10 palabras clave en filosofía política, Estella, Verbo Divino.

DRUCKER, P. (1989), Las nuevas realidades en el Estado y la política, en la economía y los negocios, en la sociedad y en la imagen del mundo, Barcelona, Edhasa.

-- (1993), The New Society, New Brunswick, Transaction Publishers.

-- (1995a), La sociedad postcapitalista, Barcelona, Apóstrofe.

-- (1995b), The Future of Industrial Man, New Brunswick, Transaction Publishers.

FERGUSON, A. (1974), Un ensayo sobre la historia de la sociedad civil, Madrid, Instituto de Estudios Políticos.

FERNÁNDEZ-PIRLA, J. M. (1962), La empresa desde el punto de vista económico, Madrid, Instituto de Estudios Políticos.

GARCÍA ECHEVARRÍA, S. (2006), Responsabilidad social corporativa: la responsabilidad social corporativa como orientación del management empresarial, Alcalá de Henares, Instituto de Dirección y Organización de Empresa.

-- (2011), Papel del beneficio en el ordenamiento económico-societario, Navarra, Empresa y Humanismo, Universidad de Navarra.

GARCÍA MARZÁ, D. (2008), "Sociedad civil: una concepción radical”, en Recerca, Revista de Pensament i Anàlisi, no 8, pp. 27-46.

GARRIGUES, J. (1976), Curso de Derecho Mercantil, I, Madrid, Imprenta Aguirre.

GINER, S. (1987), “Avatares de la sociedad civil”, en Ensayos civiles, Barcelona, Península.

GUTENBERG (1978), Economía de la empresa. Teoría y práctica de la gestión empresarial, Bilbao, Deusto.

HABERMAS, J. (1999a), Teoría de la acción comunicativa, Madrid, Taurus.

-- (1999b), Facticidad y validez, Madrid, Trotta.

-- (1999c), La inclusión del otro, Barcelona, Paidós.

HEGEL, G. W. F. (1988), Principios de la Filosofía del Derecho, Barcelona, Edhasa.

HERNÁNDEZ MARTÍN, M. A. (1988), La intervención del sector público en la economía, Salamanca, Universidad de Salamanca.

PÉREZ-DÍAZ, V. (1993), "El retorno de la sociedad civil", en La primacía de la sociedad civil, el proceso de formación de la España democrática, Madrid, Alianza.

POLO, L. (2012), Filosofía y economía, Pamplona, EUNSA.

PORTER, M.; y KRAMER, M. (2006), "Strategy and Society. The Ling Between Competitive Advantage and Corporate Social Responsibility", en Harvard Business Review, diciembre.

-- (2011), "Creating Share Value. How to reinvent capitalism - and unleash a wave of innovation and growth", en Harvard Business Review, enero-febrero.

SAMUELSON, P. (1979), Curso de Economía Moderna, Madrid, Aguilar.

TOCQUEVILLE, A. (2004), El Antiguo Régimen y la Revolución, Madrid, Istmo.

-- (2006), La democracia en América, Madrid, Fundación Iberdrola.

TOFFLER, A. (1970), El shock del futuro, Barcelona, Plaza \& Janés.

-- (1981), La tercera ola, Barcelona, Plaza y Janés.

-- (1985), La empresa flexible, Barcelona, Plaza y Janés. 
WALZER, M. (2001), "La idea de la sociedad civil. Una vía de reconstrucción social”, en Del Águila, R. y Vallespín, F. (coords.), La democracia en sus textos, Madrid, Alianza.

\section{Breve currículo:}

\section{Miguel de Haro Serrano}

Doctor en Ciencias Sociales por la Universidad Juan Carlos, de Madrid y licenciado en Derecho por la Universidad de Granada. Profesor colaborador del Master Comunicación Empresarial en la Universidad Rey Juan Carlos. Fundador y presidente de Ediciones y Estudios, creada en 1962 y editora de las publicaciones profesionales IPMARK, Distribución Actualidad y Restauración News. Creador y primer director de la Escuela de Publicidad del Centro Español de Nuevas Profesiones, de Madrid, en 1960. Fundador, expresidente y actual presidente de honor de la Asociación de Editores de Prensa Periódica (AEPP). 